EMPLOYEE COST-SHARING AND THE

WELFARE EFFECTS OF FLEXIBLE SPENDING ACCOUNTS

William Jack

Arik Levinson

Sjamsu Rahardja

Working Paper 11315 
NBER WORKING PAPER SERIES

\author{
EMPLOYEE COST-SHARING AND THE \\ WELFARE EFFECTS OF FLEXIBLE SPENDING ACCOUNTS \\ William Jack \\ Arik Levinson \\ Sjamsu Rahardja \\ Working Paper 11315 \\ http://www.nber.org/papers/w11315
}

\author{
NATIONAL BUREAU OF ECONOMIC RESEARCH \\ 1050 Massachusetts Avenue \\ Cambridge, MA 02138 \\ May 2005
}

We thank Luca Anderlini, Phil Cross, Nada Eissa, Randy Ellis, Luca Flabbi and Sherry Glied for discussions and comments. The views expressed herein are those of the author(s) and do not necessarily reflect the views of the National Bureau of Economic Research.

(C)2005 by William Jack, Arik Levinson, Sjamsu Rahardja. All rights reserved. Short sections of text, not to exceed two paragraphs, may be quoted without explicit permission provided that full credit, including () notice, is given to the source. 
Employee Cost-Charing and the Welfare Effects of Flexible Spending Accounts

William Jack, Arik Levinson, Sjamsu Rahardja

NBER Working Paper No. 11315

May 2005

JEL No. D60, H21, I18

\begin{abstract}
$\underline{\text { ABSTRACT }}$
Flexible Spending Accounts (FSAs) subsidize out-of-pocket health expenses not covered by employer-provided health insurance, making health care cheaper ex post, but also reducing the incentive to insure. We use a cross section of .rm-level data to show that FSAs are indeed associated with reduced insurance coverage, and to evaluate the welfare consequences of this shift. Correcting for selection effects we find that FSAs are associated with insurance contracts that have coinsurance rates about 7 percentage points higher, relative to a sample average coinsurance rate of 17 percent. Meanwhile, coinsurance rates net of the subsidy are approximately unchanged, providing evidence that FSAs are welfare-neutral. These results show that FSAs may explain a significant fraction of the shift in health care costs to employees that has occurred in recent years.
\end{abstract}

\author{
William Jack \\ Department of Economics \\ Georgetown University \\ Washington, DC 20057 \\ wgj@georgetown.edu \\ Arik Levinson \\ Department of Economics \\ Georgetown University \\ Washington, DC 20057 \\ and NBER \\ aml6@georgetown.edu \\ Sjamsu Rahardja \\ The World Bank \\ 1818 H St., NW \\ Washington, DC 20433 \\ srahardja@worldbank.org
}


December 15, 2005

\title{
Employee cost-sharing and the welfare effects of Flexible
}

\section{Spending Accounts*}

\begin{abstract}
Flexible Spending Accounts (FSAs) subsidize out-of-pocket health expenses not covered by employerprovided health insurance, making health care cheaper ex post, but also reducing the incentive to insure. We use a cross section of firm-level data to show that FSAs are indeed associated with reduced insurance coverage, and to evaluate the welfare consequences of this shift. Correcting for selection effects we find that FSAs are associated with insurance contracts that have coinsurance rates about 7 percentage points higher, relative to a sample average coinsurance rate of 17 percent. Meanwhile, coinsurance rates net of the subsidy are approximately unchanged, providing evidence that FSAs are welfare-neutral. These results show that FSAs may explain a significant fraction of the shift in health care costs to employees that has occurred in recent years.
\end{abstract}

Keywords: Health expenditure subsidies, moral hazard, Flexible Spending Accounts

JEL Codes: D60, H21, I18

William Jack

Georgetown University

Arik Levinson

Georgetown University

Sjamsu Rahardja

World Bank

*Jack: wgj@georgetown.edu, Levinson: aml6@georgetown.edu, Rahardja: srahardja@worldbank.org. We thank Luca Anderlini, Phil Cross, Nada Eissa, Randy Ellis, Luca Flabbi and Sherry Glied for discussions and comments. 


\section{Introduction}

For half a century, health insurance premiums paid by employers on behalf of their employees have been exempt from income taxation in the US. Analysts have long argued that this tax exemption amounts to an unbalanced subsidy for health care: insurance premiums are paid with pre-tax dollars, while out-of-pocket expenses must be paid with after-tax income. The imbalance tilts insurance towards larger premiums and smaller out-of-pocket expenses, resulting excessive coverage and inefficient overuse of medical care (Pauly 1986, Feldstein 1973).

Recently, two proposals have arisen that would balance the tax treatment of premiums and out-of-pocket health expenses. In November 2005, the President's Advisory Panel on Federal Tax Reform proposed capping the amount of health insurance that can be purchased with pre-tax dollars at the average premium (currently $\$ 5,000$ for an individual and $\$ 11,500$

for a family). This would mean that the marginal health insurance purchase for most individuals would trade off after-tax insurance premiums against after-tax out-of-pocket expenses. At the same time, others have proposed "full deductibility" of all medical expenses (Hubbard et al. 2004; Cogan et al. 2005). This would mean that marginal health purchases would trade pre-tax premiums against pre-tax out-of-pocket costs.

In this paper we examine Flexible Spending Accounts (FSAs), a 1978 policy under which some employers have allowed employees to set aside pre-tax income to pay out-of-pocket expenses. These accounts are, we believe, a good source of variation in the tax treatment of health expenses, and can be used to study two broader implications of full deductibility. 
First, we ask whether deductibility reduces the incentive to insure, increasing the premiums for health insurance offered by employers with FSAs. Second, we examine whether FSAs, by subsidizing out-of-pocket costs, reduce the inefficiency associated with subsidizing premiums in the first place.

In addition, while we do not have time-series data on FSA use and out-of-pocket costs, our study may shed light on recent increases in the employee share of health costs. Fifteen percent of large firms surveyed in 2003 intended to increase employees' coinsurance rates, and 20 percent expected to increase out-of-pocket payments for prescription drugs. Between 2001 and 2004 coinsurance rates for prescription drugs rose from 18 to 20 percent for generics, 21 to 26 percent for preferred drugs (i.e., those included on a formulary list), and from 24 to 31 percent for non-preferred drugs (Kaiser Family Foundation and HRET, 2004, page 116). These trends may be partly explained by the growing number of firms offering FSAs, and by the growing use of the accounts by employees. If out-of-pocket costs are tax subsidized via FSAs, employees may be better off trading less-generous insurance for some other form of compensation.

Employees bear insurance costs either by sharing (nominally) in the payment of premiums, ${ }^{1}$ or by being exposed to out-of-pocket costs when they use medical services, and the examples above indicate that changes are occurring on both margins. Some attention has been given in the literature to the increase in the first component (the share of premiums),

\footnotetext{
${ }^{1}$ In principle, under certain circumstances the whole premium may be borne by the employee in the form of lower wages (Gruber, 1994), but employee heterogeneity could complicate the economic incidence somewhat.
} 
focusing on changes in tax rates, demographic trends, and eligibility for public insurance such as Medicaid (Gruber and McKnight, 2003). In this paper, we focus on the second component - out-of-pocket costs borne by employees.

Employer-provided health insurance was first subsidized through the tax system under Section 106 of the 1954 Internal Revenue Service Act. The act exempts health insurance premiums paid by the employer from the employee's taxable income. As purchases of health insurance are effectively subsidized at the employee's marginal income tax rate, it is widely believed (e.g., Pauly, 1986) that the subsidy induces individuals to buy insurance through their employers, and to buy more generous insurance than they otherwise would. ${ }^{2}$

In 1978, Section 125 of the Internal Revenue Code extended the tax exemption for health insurance. Premium payments nominally made by an employee are now excludable from taxable income, so that the full premium receives a subsidy at the employee's marginal tax rate, independent of whether it is paid by the employer or employee.

Section 125 was not, however, limited to premium payments: other out-of-pocket health expenditures were made excludable from taxable income. Individuals who are offered access to so-called Flexible Spending Accounts (FSAs) can make annual contributions from pre-tax income. These tax-free funds can be used to offset qualified medical expenses, including deductibles, copayments, and coinsurance obligations that are part of an insurance policy, or simply to pay for other uninsured medical expenses. ${ }^{3}$

\footnotetext{
${ }^{2}$ It is useful to distinguish between changes in generosity on the extensive and intensive margins - plan generosity falls if certain services (mental health, maternity, etc.) are removed from coverage, or if the share of costs of services covered by the plan falls.

${ }^{3}$ Any unused funds in the FSA are forfeited at the end of the year, inducing individuals first to be
} 
Since their introduction in 1978, the use of FSAs has been growing. According to the 1993 Robert Wood Johnson Employer-Provided Health Insurance survey, about 22 percent of employers administered FSAs in 1993. The Kaiser Family Foundation reports the share of employers offering FSAs in 2003 by firm size, and finds rates of 83 percent for very large firms (up from 69 percent in 1999), 76 percent for large firms, 57 percent for midsize firms, and 14 percent for small firms. Government spending due to FSAs is significant. Tax expenditures for cafeteria plans, to which contributions for both medical care and dependent care expenses can be made, amounted to an estimated $\$ 17$ billion in 2004 (Joint Committee on Taxation, 2003).

Few studies have investigated the effects of FSAs on employer-provided health insurance. Levy (1998) shows that a firm is more likely to offer an FSA if it employs more workers with a high demand for insurance. She also finds that for firms that offer FSAs, employee premium contributions increase with the marginal tax rate. Cardon and Showalter (2001) examine the determinants of employee participation in an FSA program. Their findings suggest that participation increases with income and to a certain extent the foreknowledge of medical expenditures. Dowd, et al. (2001) study the effects of Section 125, but focus on the subsidy to employee-paid premiums, instead of the subsidy to out-of-pocket expenses. They find that the employee-paid premium subsidy, like the exclusion of employer-paid premiums, distorts employees' insurance decisions.

realistic when making initial FSA allocations, and second to accelerate expenditures near the end of the year if by then health expenses have turned out to be smaller than expected. (Recent changes allow unused FSA contributions to be rolled over for a $2 \frac{1}{2}$ month grace period in the subsequent year.) Despite these non-linearities in the subsidy regime, in most of this paper we treat the deduction of out-of-pocket expenses as open-ended. 
Two studies have suggested explanations for the rise in employee contributions to employerprovided health insurance, though neither focuses on FSAs. Gruber and McKnight (2003) find that falling marginal income tax rates, rising HMO penetration, increasing Medicaid eligibility, and rising health care costs explain more than half of the run-up in employee contributions. Dranove et al. (2000) show that the rise in two-income households explains part of the shift, as employers try to induce their employees to rely on their spouses' employers' benefits. Our study is the first to look at FSAs as a potential cause of the rise in out-of-pocket health care costs.

Identifying the effect of FSAs on health insurance choices is important for two reasons. First, it improves our understanding of trends in coverage rates over time and the likely effects of proposed tax policy changes (i.e., full deductibility) on insurance coverage. The second reason is more normative. If, by subsidizing out-of-pocket expenditures, FSAs induce further over-consumption of medical care, then FSAs will exacerbate the distortion associated with the existing subsidy to premiums. But FSAs could lead individuals to purchase plans with higher nominal coinsurance rates. If the plan characteristics respond enough to the subsidy, then effective (i.e., net-of-subsidy) coinsurance rates could increase.

If this FSA effect increases net coinsurance rates, it can partially correct the distortion introduced by the premium subsidy. Even though individuals would face higher out-ofpocket expenses, they would be better off. This theoretical possibility was first identified by Jack and Sheiner (1997), and is investigated empirically here.

We estimate the effect of an employer offering an FSA on the coinsurance rate associated 
with the employer's health plans. In the process we use IV techniques to account for selection effects. (More generous employers are likely to both provide "better" insurance, including lower coinsurance rates, and to offer FSAs.) Our estimates suggest that FSAs increase the coinsurance rate for the average health care plan by 7.3 percentage points. This is large, since the average coinsurance rate for the sample of all firms is about 17 percent. Not only is the nominal coinsurance rate higher in the presence of FSAs, but it is sufficiently higher that the effective (net-of-subsidy) coinsurance rate is approximately unchanged. This suggests that FSAs are welfare-neutral, due to the presence of the pre-existing premium subsidy.

\section{Insurance choice in the presence of FSAs}

In this section we use the model of Jack and Sheiner (1997) to motivate and guide our empirical research. We start by recalling that a fully efficient insurance policy equalizes an individual's expected marginal utility of income across uncertain states of nature. Ideally, the implied redistribution across states would be effected via lump-sum state-contingent transfers. In practice income is transferred to states of high health needs (bad states) by paying for incurred costs. Because this can lead to over-consumption of care (i.e., moral hazard), insured individuals are often required to share some of the costs of care, even in bad states (Pauly, 1968). Such cost sharing exposes individuals to some risk, but reduces the costs associated with moral hazard.

Jack and Sheiner analyze this trade-off in a simple model in which insurance contracts are characterized by a premium and a coinsurance rate - the latter being the proportion of 
incurred medical costs that must be paid out-of-pocket by an individual. A simple way to model uncertain health is to assume that the cost or price of improving health is uncertain, and is represented by a parameter $\theta \in\left[\theta_{0}, \theta_{1}\right]$. Thus, if $H$ is an individual's level of health and $C$ is his consumption of other goods, then his expenditure is $C+\theta H$. To attain the same level of health, an individual with worse health status i.e., higher $\theta$, must spend more, $\theta H$, on medical care. ${ }^{4}$

The representative consumer's (state-independent) utility is $U(C, H)$. Income, denoted by $W$, is exogenous and fixed. Given a coinsurance rate of $\kappa$ and premium $P$, in health state $\theta$ a consumer chooses health and consumption by solving the following problem:

$$
\max _{C, H} U(C, H) \text { s.t. } W-P=C+\kappa \theta H \text {. }
$$

Demand for health is denoted $H(\kappa \theta, W-P)$, and demand for the consumption of other goods is $C(\kappa \theta, W-P)$. Indirect utility is $V(\kappa \theta, W-P)=U(C(\kappa \theta, W-P), H(\kappa \theta, W-P))$.

The consumer chooses $\kappa$ and $P$ to maximize expected utility, $\Psi(\kappa, P)$, subject to the insurer's zero profit condition:

$$
\max _{\kappa, P} \Psi(\kappa, P)=\int_{\theta_{0}}^{\theta_{1}} V(\kappa \theta, W-P) d F \quad \text { s.t. } P=(1-\kappa) \int_{\theta_{0}}^{\theta_{1}} \theta H d F
$$

where $\theta$ is distributed according to the cdf $F($.$) . After rearranging and applying Roy's$

\footnotetext{
${ }^{4}$ This interpretation can be derived from a simple health production function model. Assume that $\theta$ represents generic health status, and health $H$, is produced under constant returns to scale from inputs $z$, with

$$
H=f(z, \theta)=z / \theta \text {. }
$$

Thus $\theta$ determines the productivity of health inputs. If input prices are $p$, then the minimum cost of attaining health $H$ in state $\theta$ is $c(H, \theta)=p \theta H$. If $p$ is normalized to unity, $\theta$ can be interpreted as the price of health.
} 
identity (see Jack and Sheiner, page 209), the optimal coinsurance rate satisfies

$$
\operatorname{cov}(q, \alpha)=-\bar{\alpha}(1-\kappa) \frac{d \bar{q}}{d \kappa},
$$

where $q \equiv \theta H$ is health spending, and $\alpha \equiv V_{2}$ is the marginal utility of income, both of which are state-dependent. Bars denote means. The left hand side is a measure of the expected utility cost of a marginal increase in the coinsurance rate, holding health expenditures in each state, $q$, constant. The right hand side is the corresponding marginal benefit of such an increase, deriving from the premium savings associated with reduced consumption of medical care when the coinsurance rate rises.

Figure 1 illustrates the optimal choice of insurance contract. In this figure, expected utility is increasing towards the origin. $\Pi$ is the zero profit locus. (Though we have drawn $\Pi$ as a straight line for expositional clarity, in fact it will be convex. If people respond to lower coinsurance rates by purchasing more health care, then decreases in coinsurance rates require successively larger premium increases in order to remain actuarially fair.) When the coinsurance rate is one, there is no insurance, so the premium is zero. The premium is highest when the individual is fully insured against medical costs $(\kappa=0)$. Assuming expected utility $\Psi(\kappa, P)$ is well-behaved, the optimal coinsurance rate is simply characterized by the first order condition (2), located at point $A$ and denoted $\kappa^{*}$.

The effects of the subsidy to the purchase of insurance arising from the exclusion of employer and employee premium payments can best be anticipated by focusing on the net premium, $\widetilde{P}=P(1-\tau)$, where $\tau$ is the individual's marginal income tax rate. The zero 


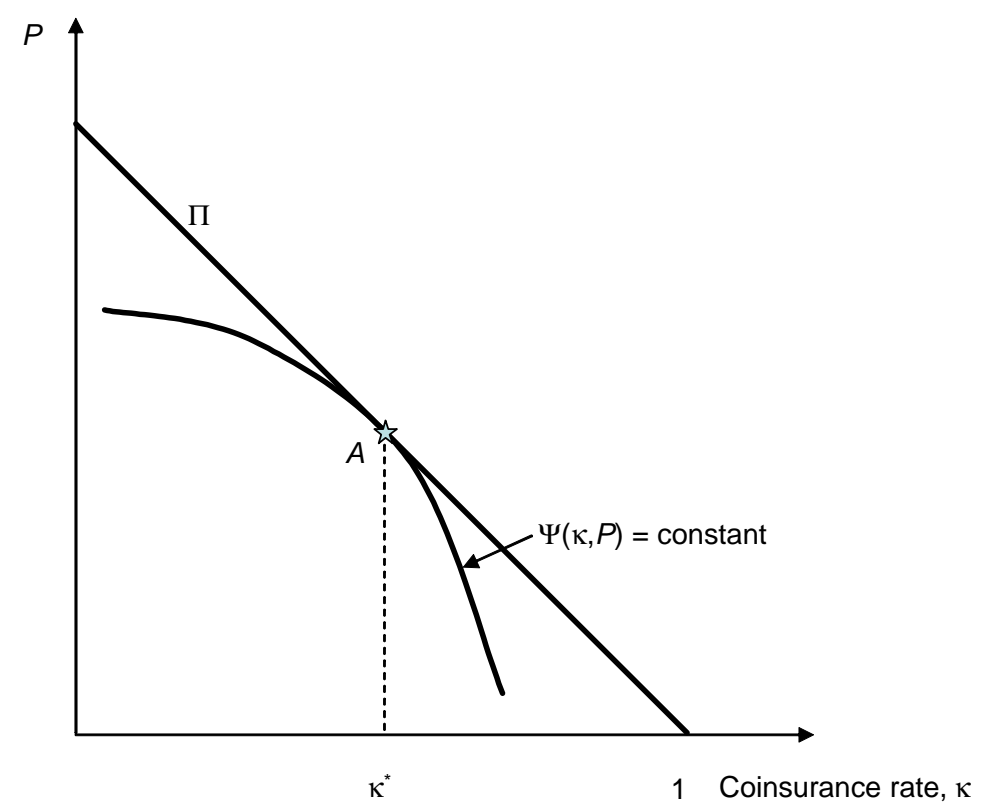

Figure 1: The optimal insurance policy

profit constraint faced by insurers can be written, in terms of the net premium, as

$$
\frac{\widetilde{P}}{(1-\tau)}=(1-\kappa) \bar{q}
$$

where $\bar{q}$ is expected health expenditures, and is a function of the coinsurance rate and the individual's income net of insurance premiums and taxes paid. This net income, in turn, is $W-(\widetilde{P}+T)$, where $T$ is a lump-sum tax used to finance the subsidy. In figure 2 the vertical axis measures the total ex ante payment associated with the purchase of health insurance, $\widetilde{P}+T$. The effect of the subsidy is thus to flatten and shift the zero profit line in figure $1 .{ }^{5}, 6$ The zero profit line in the presence of the premium subsidy is denoted $\Pi_{\tau}$.

\footnotetext{
${ }^{5}$ This can most easily be seen by supposing that $\bar{q}$ is fixed, and comparing equation (3) with the constraint in $(1)$.

${ }^{6}$ Without taking account of the tax revenue required to finance this subsidy, the new budget line would pivot around the point $\kappa=1$. However, this would be of limited use for welfare analysis.
} 


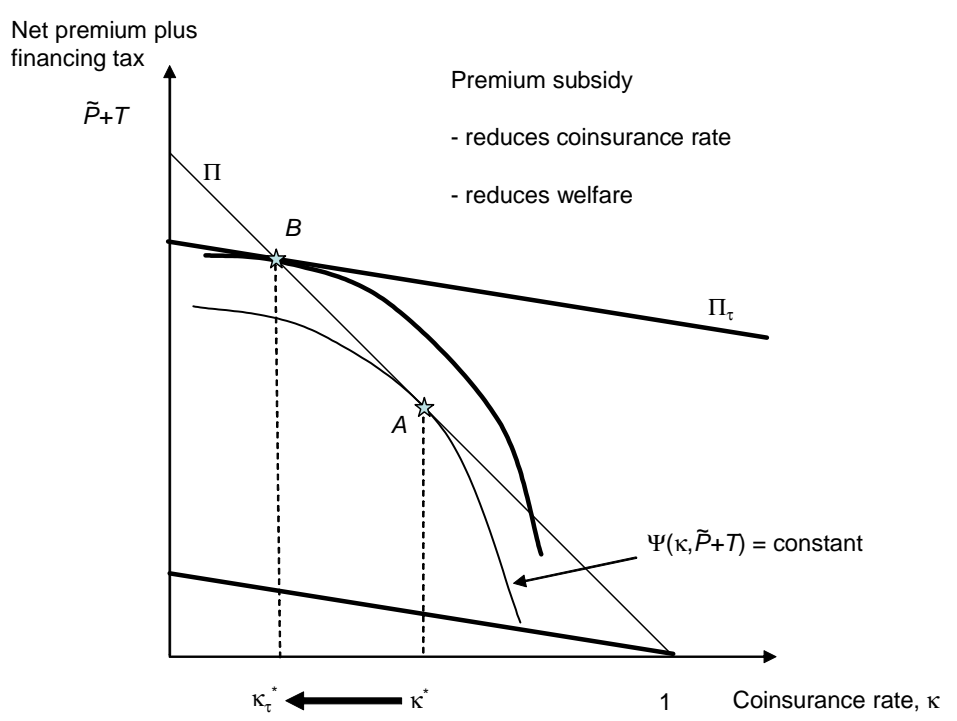

Figure 2: Optimal insurance when premiums are subsidized at a rate $\tau$

The optimal choice of insurance policy (at point $B$ ) must still lie on the old zero profit line $\Pi$, but at a point where the individual's indifference curve is tangent to $\Pi_{\tau}$. As long as the individual's preferences over $\kappa$ and $\widetilde{P}+T$ are well behaved, the subsidy induces individuals to choose more generous insurance, $\kappa_{\tau}^{*}<\kappa^{*}$ (see Jack and Sheiner, Proposition 1). Naturally, this premium subsidy, financed by a lump-sum tax is welfare-reducing, because it distorts individuals' incentives to purchase efficient health insurance policies.

Finally, if out-of-pocket expenditures are also subsidized, say at a rate $\sigma$, then the zero profit line rotates and shifts once again, this time as shown in figure 3 to $\Pi_{\tau}^{\sigma}$. In this figure, as before, the net premium (plus lump-sum tax) is shown on the vertical axis, while now the net coinsurance rate $\widetilde{\kappa}=(1-\sigma) \kappa$ is shown on the horizontal axis. The zero profit condition, in terms of $\widetilde{P}$ and $\widetilde{\kappa}$, is

$$
\frac{\widetilde{P}}{(1-\tau)}=\left(1-\frac{\widetilde{\kappa}}{(1-\sigma)}\right) \bar{q}
$$




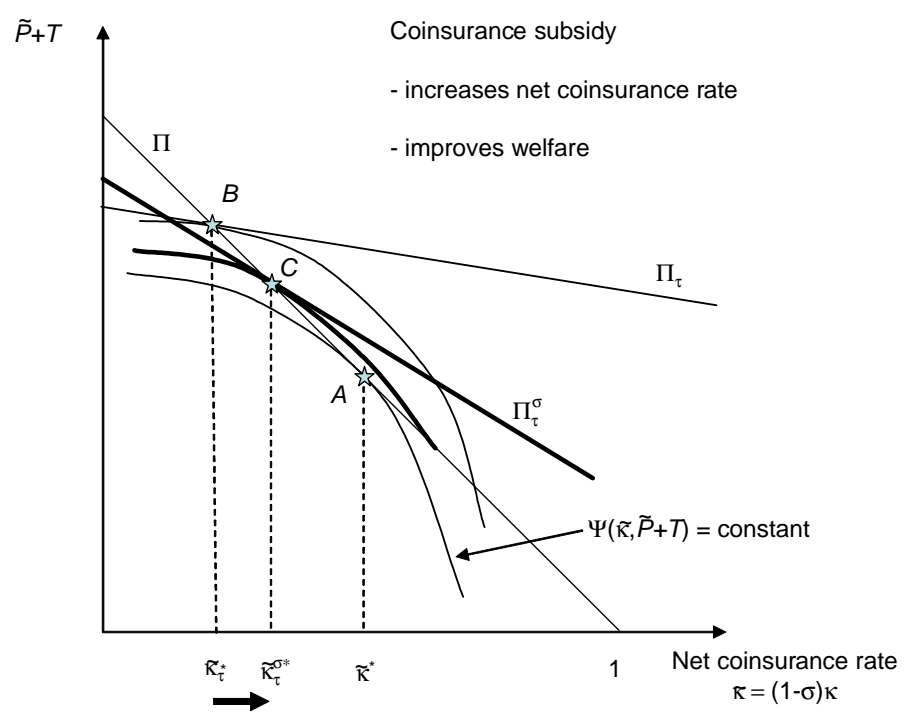

Figure 3: Optimal insurance when premiums are subsidized at a rate $\tau$ and coinsurance payments are subsidized at a rate $\sigma$

The effect of the $\sigma$-subsidy is to steepen the budget line compared with $\Pi_{\tau}$, simply because a change in net coinsurance rate of $d \widetilde{\kappa}$ corresponds to a larger change in the gross rate, $d \kappa=d \widetilde{\kappa} /(1-\sigma)$, which generates a correspondingly larger change in the premium. (Again, think of $\bar{q}$ as being fixed and compare conditions 3 and 4.) The optimal insurance policy (point $C$ ) again must lie on the old zero profit line $\Pi$, but at a point where the individual's indifference curve is tangent to $\Pi_{\tau}^{\sigma}$.

As drawn in figure 3, the effect of the subsidy to out-of-pocket payments is to increase the optimal coinsurance rate by so much that the net coinsurance rate, $\widetilde{\kappa}_{\tau}^{\sigma *}$ rises above that prevailing under the premium subsidy regime alone, $\widetilde{\kappa}_{\tau}^{*}$. This result relies on consumer indifference curves in $(\widetilde{\kappa}, \widetilde{P}+T)$-space becoming successively steeper as we move down the original budget line. Jack and Sheiner (Proposition 2) show that if the demand for health 
care is inelastic with respect to the out-of-pocket price, then a small coinsurance subsidy, $\sigma>0$, does in fact induce such a change in the net coinsurance rate. In sum, FSAs can partially undo the negative efficiency effects of premium subsidies. However, it is also

possible that indifference curves in $(\widetilde{\kappa}, \widetilde{P}+T)$-space could become steeper near the top of the original zero profit line. In this case, the $\sigma$-subsidy would induce a lower choice of net coinsurance rate, and would be welfare-reducing. The measured effect of FSAs on net coinsurance rates can thus be used to assess the welfare effects of the tax policy.

\section{Data and Empirical Strategy}

The previous section demonstrates two important potential consequences of the growth of flexible spending accounts. First, subsidizing out-of-pocket expenses could cause a nominal shift in health care costs from employers to employees. It would be ironic if public policy were in part accountable for this phenomenon that has, rightly or wrongly, generated so much concern. Second, it is possible that the incremental subsidy to out-of-pocket expenses, in the form of FSAs, mitigates the welfare loss from the underlying subsidy to premiums. As illustrated by figure 3 , the resulting shift towards insurance policies with higher coinsurance rates and lower premiums would be efficiency enhancing so long as the net coinsurance rate with the subsidy in place is higher than the gross coinsurance rate would have been without the subsidy. 


\subsection{Data}

To investigate these issues empirically we use the 1993 Employer Health Insurance Survey (EHIS) from the Robert Wood Johnson Foundation. The EHIS is a cross-section of firmlevel data on health insurance plans offered by employers in 10 U.S. states. The survey has two parts. The first has information about health insurance plans, including their coverage, premiums, and coinsurance rates. The second part contains information about the firms, including their industrial classifications, employees, payrolls, unionization rates, and organizational forms.

We focus on a subsample of the EHIS comprising 6525 firms that offer health insurance to their employees, have payrolls per worker greater than the full-time minimum wage, and offer at least one insurance plan that is not an HMO or a PPO. In this sample, 25.8 percent of the plans are associated with firms that offer employees access to FSAs, and the firms offer a total of 7391 different insurance plans.

The EHIS is the best publicly available source to examine the potential effects of deductibility for out-of-pocket health expenses. However, it has a number of limitations. First, although one motive for our study is to explain the recent growth in out-of-pocket costs borne by employees, we recognize that the 12-year-old data in the EHIS cannot directly address this issue. Nonetheless, we expect that the mechanisms by which FSAs affect the structure of insurance policies are likely to have remained operative over time.

Second, while we have information about the various insurance policies offered by firms, we do not know the take-up rates for different policies within each firm. For most of the 
paper, our unit of observation is the insurance plan. We recognize that some unobserved plan characteristics may be correlated across plans within firms, and we test the robustness of our results by running some specifications where the unit of observation is the firm, and plan characteristics (e.g. coinsurance rates) are simple averages across all the plans offered by each firm.

Third, out-of-pocket payments come in a variety of forms: deductibles, copayments, and coinsurance rates, often with some sort of annual cap. For this project we want some indicator of the out-of-pocket expenses associated with a health insurance plan. As a compromise, we focus on the coinsurance rate: the share of costs borne by the employee, after the deductible has been met, but before any maximum out-of-pocket cost, expressed as a percentage. Since HMO and PPO plans typically do not include proportional cost-sharing (instead relying on other mechanisms to control demand), we exclude them from our sample.

Table 1 provides descriptive statistics for these data. Consistent with our expectations based on section 2, health insurance plans offered by firms with FSAs have lower premiums and higher coinsurance rates. Of course, plans associated with FSAs also differ in many other respects. They are more likely to cover certain services, and the firms that offer them have more and better-paid employees, have been in existence longer, and are less likely to be unincorporated and for-profit. ${ }^{7}$

The key determinant of the value of the FSA subsidy, and of the welfare consequences

\footnotetext{
7 For Blue Cross/Blue Shield policies only, the coinsurance rates are 15.1 for the 1791 plans with FSAs, and 17.0 for the 506 plans without. The difference (of means) is easily statistically significant. Of course, we do not want to interpret this literally any more than the difference in coinsurance rates for all plans in table 1 .
} 
of FSAs, is the marginal income tax rate faced by the plan's members, $\tau$. Since we do not know the true marginal tax rates faced by each plan's members, we use the NBER TAXSIM model to construct a proxy. First we compute the average earned income per worker for each firm, and we assume this constitutes these employees' entire incomes. We then let TAXSIM compute the federal and state marginal tax rates by assuming that all workers are single taxpayers with no dependents and standard deductions. Finally, we add 7.65 percent to account for payroll taxes (6.2 percent for Social Security and 1.45 percent for Medicare). ${ }^{8}$

These calculated average marginal tax rates vary across observations due to differences in firms' payrolls and in states' marginal tax rates. Firm differences account for about 85 percent of the variation in $\tau$, and state differences account for the remainder. As table 1 shows, individuals with health plans associated with FSAs have higher estimated marginal tax rates.

Table 1 shows that health plans associated with FSAs have higher coinsurance rates, lower premiums, and members that are likely to face higher marginal tax rates. To ask whether FSAs may have caused the increase in employee out-of-pocket payments, and whether the net after-tax coinsurance rate is higher than the gross rate would be without the FSA subsidy, we need to control for differences between firms with and without these accounts.

\footnotetext{
8 While we do not attempt to approximate the economic incidence of these taxes, it does not matter what fraction we add to state and federal taxes so long as we use the same fraction for all of the plans. We revisit this issue below when we discuss the effect of FSAs on net-of-tax coinsurance rates.
} 


\subsection{Empirical strategy}

Ideally, we would like to assess the effect of subsidizing out-of-pocket expenses (offering an FSA) on the average health care plan's coinsurance rate. Estimating this average treatment effect faces two distinct problems, one relating to endogenous regressors, and the other to selection effects.

First, since coinsurance rates and premiums are structurally related through the zero profit constraint (illustrated in figure 1), an econometric model that hopes to identify the effect of FSAs on coinsurance rates must control also for premium differences across plans, among other characteristics. However, the observed variation in premiums is unlikely to be exogenous, and a simple OLS estimate of the premium effect may be biased, thereby

contaminating the estimate of the FSA effect. Instead, we estimate a reduced form where the coinsurance rate is estimated as a linear function of exogenous variables that affect premiums, and which should not in theory affect the coinsurance rate. These include state indicator variables (to account for regional health care cost differences), plan coverage, firm size and unionization rates.

The second obstacle to estimating whether coinsurance rates are higher for firms with FSAs is that firms' decisions to offer FSAs are not exogenous. Some firms may simply have better employee benefits than others. These firms may have more generous health insurance plans, lower coinsurance rates, FSA programs, and a host of other unmeasured attributes. An unmeasured characteristic such as this, which is correlated with both the propensity to offer FSAs and to have low coinsurance rates, will likely bias any estimate of the impact of 
FSAs on coinsurance rates against finding a positive effect. In other words, for the average firm, adopting an FSA could in theory cause it to have higher coinsurance rates. But firms that have adopted FSAs are the generous ones, which also have lower coinsurance rates. A simple regression of coinsurance rates that fails to account for the endogenous decision to adopt an FSA will likely understate the positive effect of FSAs on coinsurance rates.

To control for the endogeneity of FSAs, we use the procedure outlined in Heckman and Robb (1985) for dealing with discrete endogenous variables. We first estimate a probit of whether or not the firm has an FSA, and we include in that regression a set of instruments that are not included in the determinants of coinsurance rates. These instruments include the firm's age, whether the firm has plants located in other states, whether the firm has local competitors, and the percentage of the firm's employees eligible for health insurance. These firm characteristics predict the likelihood of a firm offering an FSA, but are unlikely to be related to the coinsurance rates of employees.

We make two alternative parametric assumptions in estimating the treatment effect. Our first is that the treatment effect is independent of the observable characteristics $X$,

$$
\kappa=X \beta+F \gamma+\nu
$$

where $X$ is a matrix of covariates, $F$ is a vector of dummy variables equal to one if the plan's firm has an FSA, and $\gamma$ is the parameter we are interested in. We still cannot estimate (5) using OLS, because $\operatorname{corr}(F, \nu) \neq 0$. Unobserved characteristics of firms that make them likely to provide generous benefits including FSAs and low coinsurance rates will bias estimates of $\gamma$. Instead, we predict the binomial indicator $F$ using a probit regression, including variables 
$Z$ not included in $X$. We then use the predicted probabilities as instruments in (5).

Our second specification weakens the ignorability of treatment assumption inherent in (5). We continue to assume that in the absence of an FSA the conditional expectation of a plan's coinsurance rate is a linear function of observable covariates. However, we now allow the treatment effect itself to be related to the covariates.

$$
\kappa=X \beta+F \gamma+F(X-\bar{X}) \delta+e
$$

where $\gamma$ is the average treatment effect (or more precisely, the treatment effect at the average value of the covariates). We estimate (6) instrumenting for $F$.

In sum, the methodology is as follows. First we estimate $P(F S A=1 \mid X, Z)$ by a probit, where $Z$ is a vector of instruments. Second, we estimate equations (5) and (6) using instrumental variables, where the difference is that (6) includes interactions between the FSA dummy and the difference between the covariates and their means.

As instruments we use the age of the firm, dummy variables for whether the firm has outof-state locations or in-state competitors, and the percentage of employees eligible for health insurance. Firm age works well as an instrument because older firms are more likely to offer FSAs, but it is difficult to imagine reasons why older firms should have different coinsurance rates from newer firms, all else equal. We include a dummy variable for multi-state firms, because they might have economies of scale in administering payroll programs such as FSAs, and on the theory that having affiliates in multiple states is more likely exogenous than the level of employment. A dummy variable for the presence of in-state competitors captures the degree of local labor market competition, putting pressure on companies to provide benefits 
such as health insurance and FSAs. Finally, the percentage of the firm's employees eligible for health insurance should increase the firm's tendency to administer an FSA. All of the results that follow are robust to the exclusion of any one of these instruments, and none of them are statistically significant themselves when included in (5) and (6).

Table 2 presents the results of this first-stage probit, which estimates the probability that a firm offers an FSA. The unit of observation is a firm-specific health insurance plan. The first five covariates listed in table 2 are the instruments, $Z$, and are excluded from the second stage regressions of coinsurance rates. Health insurance plans are more likely to be associated with firms that offer FSAs if those firms are older, have more employees eligible to participate in health insurance benefits, have locations in multiple states, and have local competition. Each 10 years of firm age adds about 1.5 percentage points to the probability that a firm offers an FSA. Each 10 percent increase in the share of employees eligible for health insurance adds about 1 percentage point to the probability of offering an FSA. And having no identified competitors subtracts about 11 percentage points from the probability of offering an FSA. These firm characteristics are clearly correlated with the probability that the firm offers an FSA. Our assumption, tested below, is that they are uncorrelated with the error term in equations (5) and (6).

Turning to the exogenous covariates in table 2, each 10 percent increase in our estimate of employees' marginal tax rates increases the probability of a firm offering an FSA by 3 percentage points. Each 10 percent increase in the fraction of female employees increases the FSA probability by 0.6 percentage points. Plans associated with non-profit firms are 8 
percentage points more likely to have FSAs. The more benefits a plan offers, the more likely it is to be associated with an FSA: prescription drug coverage increases FSA probabilities by 3 percentage points; alcoholism coverage increases it by 7 percentage points; and maternity benefits by 11 percentage points.

Some characteristics decrease the probability that a firm offers an FSA. A 10 percent increase in union membership decreases the FSA probability by 0.5 percentage points. A 10 percent increase in the fraction of workers 55 or older decreases the FSA probability by 1.5 percentage points. Unincorporated firms are 5 percentage points less likely to offer FSAs.

Firms in mining and manufacturing, and transport and communications, are more likely to have FSAs than the omitted industry, agriculture. Firms in North Dakota are more likely to have FSAs, while in other states are less likely to have FSAs than the omitted state, Colorado.

Our next step is to use the predicted probabilities of a plan being provided in conjunction with an FSA, using the coefficients in table 2, in an IV estimation of equations (5) and (6).

\subsection{Results}

Table 3 presents our central estimates of equations (5) and (6). As a benchmark, column (1) presents a simple OLS version of (5), not accounting for the selection by firms as to whether or not to offer an FSA. The dependent variable is the coinsurance rate, expressed as a number between 0 and 100. The coefficient on the FSA dummy indicates that health insurance plans associated with firms that offer FSAs have coinsurance rates that are 0.74 percentage points greater than otherwise similar plans without FSAs. Though the coefficient 
is statistically significant and in the direction we expect, the magnitude is quite small.

Column (2) of table 3 runs the same OLS specification, but includes interactions between the FSA dummy and the difference between each of the firm and insurance-plan characteristics and its mean, as in equation (6). Because the interaction included is differences-frommeans, we can interpret the FSA coefficient (1.365) in the same way as when the interaction was not included, as an average treatment effect. Here the effect has risen as a result of including the interactions, from .74 to 1.36 , but it remains small.

Of course, the decision to offer an FSA is not exogenous, and may be based on unobserved firm characteristics that also affect the coinsurance rates. In fact, we suspect that the OLS results in columns (1) and (2) understate the true effect of FSAs on coinsurance rates, because firms that have adopted FSAs have generally more generous benefits, including low coinsurance rates. Hence, we do not emphasize these first two benchmark columns.

Column (3) of table 3 shows the results of an instrumental variables estimation of equation (5), using the predicted probabilities from table 2 as instruments. The average health care plan has a coinsurance rate that is 4.07 percentage points higher when offered in conjunction with an FSA than in the absence of an FSA, controlling for observable characteristics of firms, and for the selection by firms as to whether to offer an FSA. The average coinsurance rate in the sample is 17 percent, so a 4 percent increase amounts to a substantial average treatment effect (more on magnitudes below).

In column (4) of table 3 we estimate equation (6) using IV, including interaction terms between the predicted FSA probability and the difference between the exogenous variables 
and their means. While few of the interactions are individually statistically significant, an $F$ test rejects the joint hypothesis that all of these interactions have zero effect on coinsurance rates. In other words, the covariates $X$ have different overall effects on coinsurance rates depending on whether the health insurance plan is associated with an FSA. Omitting the interactive terms biases the results in column (3). The average treatment effect reported in column (4) of table 3 suggests that when provided in conjunction with FSAs, plans have coinsurance rates that are 7.3 percentage points higher than in the absence of FSAs.

At the bottom of column (3) we report the $F$-statistic from a Wu-Hausman test of the exogeneity of the FSA regressor in column 1, easily rejecting unbiasedness and consistency for the OLS approach. Note also that the coefficients in columns (3) and (4) are larger than their OLS versions in columns (1) and (2), suggesting that the endogeneity of FSAs biases the OLS approach against finding a large average treatment effect. To interpret the size of this effect more concretely, we turn to an explicit discussion of magnitudes.

\subsection{Magnitudes and welfare implications}

In the theory illustrated in figure 3 , the subsidy to out-of-pocket costs increases the optimal coinsurance rate by so much that the net coinsurance rate rises above what it would have been absent the subsidy. Under the assumptions of inelastic demand for health care made by Jack and Sheiner (1997), subsidizing out-of-pocket costs increases the net coinsurance rate in this way, and is efficiency enhancing in the presence of a pre-existing premium subsidy.

To assess whether in fact net coinsurance rates rise as a consequence of FSAs, consider the relationship between the predicted gross and net rates, evaluated at the means of the 
covariates. The predicted gross coinsurance rate with FSAs is simply the predicted gross rate without FSAs plus the average treatment effect, $\gamma$, measured in column (4) of table 3 as 7.3 percentage points,

$$
\widehat{\kappa}^{1}=\widehat{\kappa}^{0}+\gamma
$$

The net coinsurance rate is just the gross rate times $(1-\bar{\tau})$ for plans with FSAs (where $\bar{\tau}$ is the average marginal tax rate faced by individuals in those plans), and the gross rate itself for plans without FSAs,

$$
\begin{aligned}
\widetilde{\kappa}^{0} & =\widehat{\kappa}^{0} \\
\widetilde{\kappa}^{1} & =\widehat{\kappa}^{1}(1-\bar{\tau})
\end{aligned}
$$

where net rates are denoted by $\mathrm{a}^{\sim}$.

The difference between the predicted net coinsurance rates of a plan with the average covariates with and without an FSA is defined as

$$
\Delta \widetilde{\kappa}=\widetilde{\kappa}^{1}-\widetilde{\kappa}^{0}
$$

In the top row of table 4 we present estimates of $\Delta \widetilde{\kappa}$. Using our specification from table 3 , column (4), the expected net coinsurance rate without an FSA is 15.6 percent (column (2)), while with an FSA it is 15.71 percent (column (3)). The difference, $\Delta \widetilde{\kappa}$, is 0.15 percentage points. Though positive, this increase is small and statistically insignificant, indicating that the FSA subsidy neither increases nor decreases net coinsurance rates. This calculation of $\Delta \widetilde{\kappa}$ depends on the tax rate. If we include all of the payroll taxes (15.3 percent), then the net coinsurance rate rises to 17.5 percent (instead of the 15.7 percent in table 4 ), and 
our estimate of $\Delta \widetilde{\kappa}$ suggest that net coinsurance rates rise by 1.9 percentage points, though this effect remains statistically insignificant. If we include none of the payroll taxes, the net coinsurance rates fall to 14.0 percent, and $\Delta \widetilde{\kappa}$ suggests net coinsurance rates fall 1.6 percentage points, also statistically insignificant. In sum, FSAs appear to have increased health insurance plans' coinsurance rates by a sufficient amount to erase the tax advantages of participating in the plans. As suggested by figure 3, the FSA subsidy to out-of-pocket costs is therefore welfare-neutral.

\subsection{Robustness}

The rest of table 4 presents alternative specifications. First, in row 2 we report the predicted effect of FSAs on coinsurance rates if we use a linear probability model to predict FSA choice at the first stage, instead of a probit. The estimated effects are little affected by this change in specification.

Next, some readers may be concerned that our sample of 7391 insurance plans really only involves 6525 different firms. As one check, we include the number of plans offered by the firm as an additional control variable. (These include HMOs and PPOs not counted among our 7391 original observations.) This change has little effect on our central estimate, raising it from 7.31 to 7.78 .

We also tried a specification where the unit of observation is the firm rather than the insurance plan. For each firm we simply averaged the characteristics (coinsurance rate, etc.) across all the offered plans. Here the central estimate (5.96) is still large and statistically significant, though perhaps muted slightly by the averaging of plan characteristics. 
A final set of robustness checks uses alternative sets of instruments for predicting FSAs. Recall that the instruments used in table 2 include (i) the firm's age, (ii) the percent of employees eligible for health insurance, (iii) whether the firm has locations in other states, and (iv) whether the firm has a competitor in the same state. We did not include the number of employees at a particular location as an instrument, thinking that would be correlated with the size of the risk pool, and therefore the coinsurance rate. It turned out not to be significant in the second stage regressions, and so in row 5 of table 4 we report the results of including the number of employees as an additional instrument. The main

effect (6.25), remains large and statistically significant. In the bottom panel of table 4 we report the average and net treatment effects for alternative sets of instruments, where each alternative involves dropping one of the original set. In each case, we include the dropped instrument in the second-stage coinsurance regression, and for each specification its coefficient is small and statistically insignificant. The estimates are all similar, and result in large, statistically significant average treatment effects. Moreover, each estimate results in a small and statistically insignificant net treatment effect, suggesting that FSAs have had no net effect on welfare.

\section{Conclusions}

Individuals with private health insurance in the United States have been paying an increasing share of their health care expenses out of pocket over the last decade. While this is likely due to a number of factors (demographics, falling tax rates, changes in the organization 
of health care delivery, etc.), one factor that may be important is the growth of Flexible Spending Accounts, which subsidize out-of-pocket payments. The potential role of this subsidy suggests that the observed shift to uninsured expenses may be partly illusory - net of the subsidy, out-of-pocket expenses have remained approximately constant.

In this paper, we have used cross-sectional data from an employer survey to address the link between the availability of FSAs and coinsurance rates. Of course, without panel data we cannot be definitive about the recent evolution of insurance arrangements in the US. Nevertheless, the cross-sectional analysis is instructive. We find, for example, that when health insurance is offered in conjunction with an FSA, the coinsurance rate is higher. Correcting for selection bias, the FSA effect is statistically significant and economically large: coinsurance rates are on average about 7.3 percentage points higher with FSAs than without (compared to a sample average of 17 percent). In addition, our results suggest that the shift to out-of-pocket spending is approximately welfare neutral, as the net-of-subsidy coinsurance rate is approximately equal for plans offered in the presence of FSAs.

Why might FSAs not increase net-of-tax coinsurance rates and welfare? For one, not all employees participate in the plans. Our measured effect, 7.3 percentage points, would surely be higher if all employees participated. Second, average marginal tax rates probably overstate the benefits of FSAs, because the plans involve complicated reimbursement accounts and a use-it-or-lose-it feature. If FSAs benefited all employees or were a straightforward tax deduction, their gross effect might be larger, and net-of-tax coinsurance rates and welfare might well increase. 
Finally, we believe there is a curious irony in the gap between our findings here and the public concern about shifting health care costs from employers to employees. First, it is ironic that public policy in the form of FSAs may be accountable for part of the transfer of costs to employees. Second, the fact that the shift is large enough to offset the subsidy (FSAs do not cause net coinsurance rates to fall) means that the shift in costs may not be a cause for concern. FSAs do not seem to lower welfare, and could even increase it, since they partially offset the distortionary effect of the tax subsidy given to employer-paid health insurance premiums.

\section{References}

Cardon, James and Mark Showalter (2001): "An examination of flexible spending accounts," Journal of Health Economics 20: 935-954

Cogan, John F., R. Glenn Hubbard, Daniel P. Kessler (2005): Healthy, Wealthy, and Wise, Washington DC: AEI Press.

Cooper, Phillip and Barbara Schone (1997): "More offers, fewer takers for employmentbased health insurance: 1987 and 1996," Health Affairs, 16, 142-149

Dowd, Brian, Roger Feldman, Matthew Maciejewski, and Mark Pauly, (2001): "The effect of tax-exempt out-of-pocket premiums on health plan choice," National Tax Journal 54(4): 741-756.

Dranove, David, Kathryn Spier and Laurence Baker (2000): "'Competition' among employers offering health insurance," Journal of Health Economics, 19: 121-140.

Farber, Henry and Helen Levy (2000): "Recent Trends in Employer-Sponsored Health Insurance: Are Bad Jobs Getting Worse?" Journal of Health Economics, 19: 93-119.

Feenberg, Daniel and Elisabeth Coutts "An Introduction to the TAXSIM Model", Journal of Policy Analysis and Management, 12(1).

Feldstein, Martin S. (1973): "The Welfare Loss of Excess Health Insurance," Journal of Political Economy, 81(2), 251-80. 
Gruber, Jonathon (1994): "The incidence of mandated maternity benefits," American Economic Review, 84(3), 622-41

Gruber, Jonathon and Robin McKnight (2003): "Why Did Employee Health Insurance Contributions Rise?" Journal of Health Economics, 22(6), 1085-1104

Heckman, James J. and Richard Robb (1985). "Alternative methods for estimating the impact of interventions," in James J. Heckman and Burton Singer (eds.), Longitudinal Analysis of Labor Market Data. Cambridge University Press 1985, Cambridge.

Hubbard, R. Glenn, John F. Cogan, Daniel P. Kessler (2004): "Brilliant Deduction," Wall Street Journal December 8.

Jack, William and Louise Sheiner (1997): "Welfare-improving health expenditure subsidies," American Economic Review, 87(1), 206-21

Joint Committee on Taxation (2003): "Estimates of Federal Tax Expenditures for Fiscal Years 2004-2008," JCS-8-03, US Government Printing Office, Washington DC.

Kaiser Family Foundation and Health Research and Educational Trust (2004): Employer Health Benefits: 2004 Annual Survey, Menlo Park, California, and Chicago, Illinois

Levy, Helen (1998): "Who pays for health insurance? Employee contributions to health insurance premiums," Working Paper \#398, Industrial Relations Section, Princeton University

Pauly, Mark (1968): "The economics of moral hazard: comment," American Economic Review, 58, 531-37

Pauly, Mark (1986): "Taxation, health insurance and market failure in the medical economy," Journal of Economic Literature, 24, 629-675

Wooldridge. Jeffrey M. (2002). Econometric Analysis of Cross Section and Panel Data. MIT Press, Cambridge, Massachusetts. 
Table 1. Data Summary Statistics

\begin{tabular}{|c|c|c|c|c|}
\hline \multirow[b]{2}{*}{ Insurance plan characteristics } & \multicolumn{2}{|c|}{$\begin{array}{c}\text { No FSA } \\
{[n=5487]}\end{array}$} & \multicolumn{2}{|c|}{$\begin{array}{l}\text { With FSA } \\
{[n=1904]}\end{array}$} \\
\hline & Mean & Std.dev & Mean & Std.dev \\
\hline Single premium & 160.3 & 77.1 & $152.7 *$ & 66.6 \\
\hline Family premium & 392.4 & 159.7 & $385.1^{\dagger}$ & 135.5 \\
\hline Coinsurance rate $^{\mathrm{a}}$ & 16.8 & 10.7 & $17.7^{*}$ & 8.7 \\
\hline Copayment & 8.38 & 5.36 & 8.85 & 4.33 \\
\hline Deductible & 349.7 & 399.0 & 347.6 & 365.9 \\
\hline Employer share of single premium & 83.3 & 25.4 & 80.5 & 21.9 \\
\hline Employer share of family premium & 64.7 & 34.6 & 64.8 & 27.8 \\
\hline Blue Cross/Blue Shield & 0.33 & 0.47 & $0.27 *$ & 0.44 \\
\hline Covers prescription drugs & 0.83 & 0.37 & 0.92 & 0.26 \\
\hline Covers prenatal & 0.88 & 0.32 & $0.96^{*}$ & 0.19 \\
\hline Covers dental & 0.28 & 0.45 & $0.35 *$ & 0.48 \\
\hline Covers maternity & 0.88 & 0.32 & $0.97 *$ & 0.16 \\
\hline Covers alcoholism related illness & 0.86 & 0.35 & $0.95^{*}$ & 0.21 \\
\hline \multirow[t]{2}{*}{ Limits out-of-pocket expenses } & 0.89 & 0.31 & $0.95 *$ & 0.21 \\
\hline & \multicolumn{2}{|c|}{$\begin{array}{c}\text { No FSA } \\
{[n=5039]}\end{array}$} & \multicolumn{2}{|c|}{$\begin{array}{c}\text { With FSA } \\
{[n=1486]}\end{array}$} \\
\hline Firm characteristics & Mean & Std.dev & Mean & Std.dev \\
\hline Number of plans offered & 1.34 & 0.81 & $1.89 *$ & 1.39 \\
\hline Proportion of self insured & 0.19 & 0.39 & $0.47 *$ & 0.50 \\
\hline Number of employees in the location & 44.2 & 151.3 & $154.6^{*}$ & 405.7 \\
\hline Firm's age & 28.9 & 27.0 & $44.0 *$ & 38.4 \\
\hline Percent employees older than 54 years old & 12.0 & 16.8 & $9.6^{*}$ & 12.0 \\
\hline Percent female employees & 40.7 & 28.8 & $46.1^{*}$ & 29.9 \\
\hline Percent employees joining labor union & 5.8 & 20.1 & 6.7 & 19.4 \\
\hline Marginal tax rate $(\%)$ & 31.3 & 7.4 & $32.6^{*}$ & 7.8 \\
\hline Payroll per worker $(000)$ & 25.4 & 18.3 & $28.0 *$ & 19.8 \\
\hline Percent employees eligible for $\mathrm{HI}$ & 86.7 & 23.2 & $89.4^{*}$ & 19.1 \\
\hline Percent with corporate type & 0.80 & 0.40 & 0.79 & 0.41 \\
\hline Percent with un-incorporated type & 0.11 & 0.32 & $0.06 *$ & 0.23 \\
\hline Percent with non-profit type & 0.09 & 0.29 & $0.16^{*}$ & 0.36 \\
\hline Percent with no competitor in the state & 0.82 & 0.38 & $0.77 *$ & 0.42 \\
\hline Percent have location in other states & 0.37 & 0.48 & $0.65 *$ & 0.46 \\
\hline
\end{tabular}

Source: RWJ Employer Health Insurance Survey 1993.

Notes: Private firms offering health insurance with non-missing values of variables above. 7391 insurance plans for 6525 firms, 1486 of which offer an FSA program. States are CO, FL, MN, NM, NY, ND, OK, OR, VT and WA.

$*, \dagger$ difference of sample means or proportions is significant at $5 \%$ and $10 \%$, respectively

${ }^{a}$ Twenty percent (1456) of the plans had coinsurance rates of zero. 
Table 2. First-Stage Probit of FSA Offering

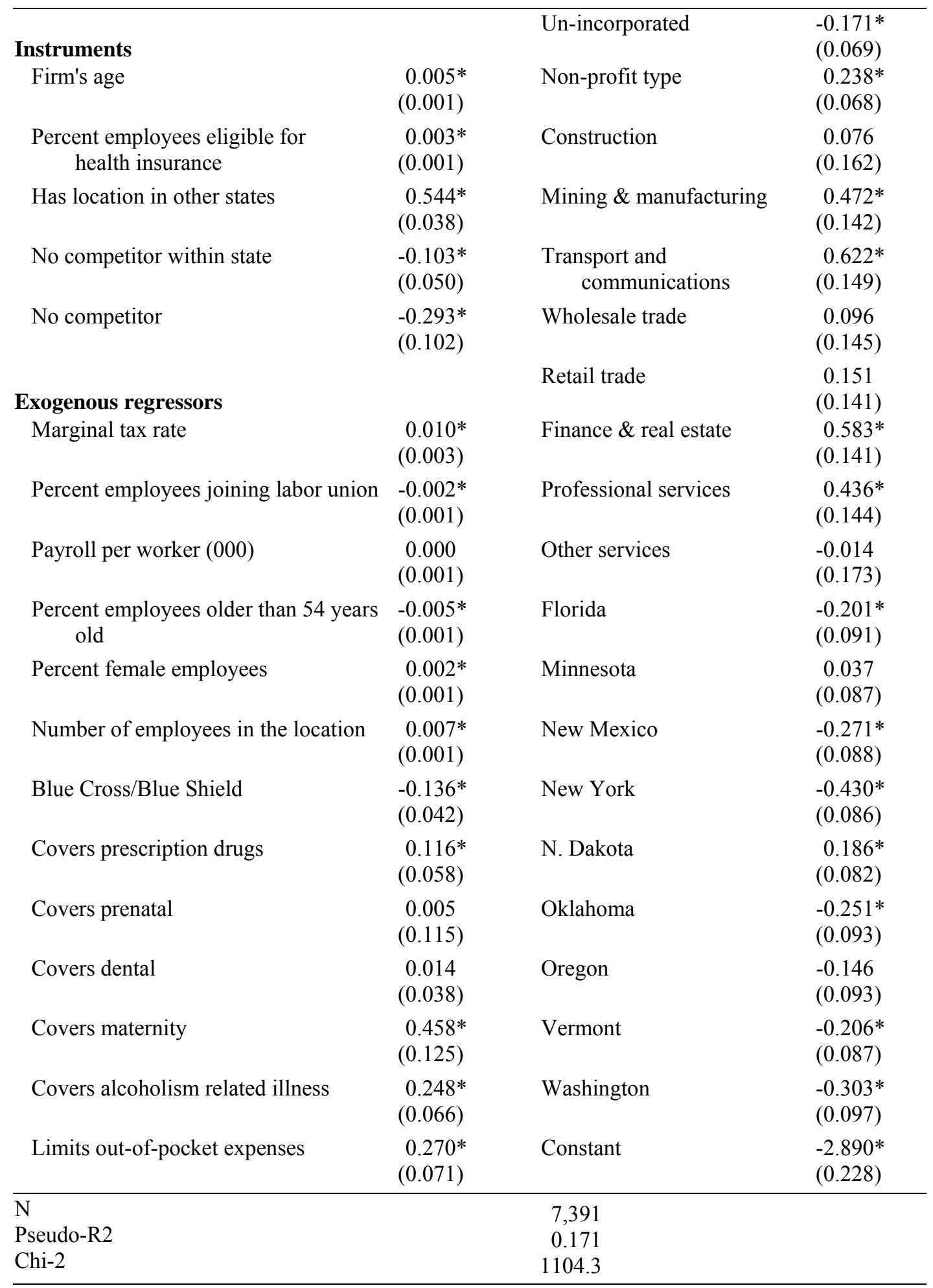

Robust standard error in parenthesis. * significant at $5 \%$. 
Table 3. Estimation Results of the Coinsurance Equation

\begin{tabular}{|c|c|c|c|c|}
\hline \multirow[b]{2}{*}{$\begin{array}{l}\text { Dependent variable: } \\
\text { coinsurance rate }\end{array}$} & \multicolumn{2}{|c|}{ OLS } & \multicolumn{2}{|c|}{ IV } \\
\hline & (1) & (2) & (3) & (4) \\
\hline \multirow[t]{2}{*}{$\overline{\text { FSA }}$} & $0.742 *$ & $1.365^{*}$ & $4.069 *$ & $7.312 *$ \\
\hline & $(0.262)$ & $(0.342)$ & $(1.005)$ & $(1.927)$ \\
\hline \multirow{2}{*}{$\begin{array}{l}\text { Percent employees joining } \\
\text { labor union }\end{array}$} & $-0.011^{*}$ & $-0.012^{\dagger}$ & $-0.010^{\dagger}$ & -0.006 \\
\hline & $(0.005)$ & $(0.006)$ & $(0.005)$ & $(0.009)$ \\
\hline \multirow[t]{2}{*}{ Marginal tax rate } & 0.026 & 0.023 & 0.010 & 0.020 \\
\hline & $(0.024)$ & $(0.028)$ & $(0.025)$ & $(0.042)$ \\
\hline \multirow[t]{2}{*}{ Payroll per worker $(000)$} & -0.009 & 0.001 & -0.010 & -0.006 \\
\hline & $(0.010)$ & $(0.012)$ & $(0.010)$ & $(0.018)$ \\
\hline \multirow{2}{*}{$\begin{array}{l}\text { Percent employees older } \\
\text { than } 54 \text { years old }\end{array}$} & -0.011 & -0.012 & -0.008 & -0.005 \\
\hline & $(0.007)$ & $(0.008)$ & $(0.008)$ & $(0.012)$ \\
\hline \multirow[t]{2}{*}{ Percent female employees } & 0.007 & 0.009 & 0.004 & 0.005 \\
\hline & $(0.005)$ & $(0.006)$ & $(0.005)$ & $(0.010)$ \\
\hline \multirow{2}{*}{$\begin{array}{l}\text { Number of employees in the } \\
\text { location }\end{array}$} & 0.006 & 0.009 & -0.004 & -0.015 \\
\hline & $(0.004)$ & $(0.007)$ & $(0.005)$ & $(0.038)$ \\
\hline \multirow[t]{2}{*}{ Blue Cross/Blue Shield } & -1.174 & $-1.586^{*}$ & $-0.967 *$ & $-2.090^{*}$ \\
\hline & $(0.286)$ & $(0.332)$ & $(0.299)$ & $(0.508)$ \\
\hline \multirow[t]{2}{*}{ Covers prescription drugs } & 0.204 & 0.332 & 0.063 & -0.541 \\
\hline & $(0.401)$ & $(0.445)$ & $(0.402)$ & $(0.687)$ \\
\hline \multirow[t]{2}{*}{ Covers prenatal } & 0.690 & 1.008 & 0.682 & $3.199^{\dagger}$ \\
\hline & $(0.841)$ & $(0.905)$ & $(0.839)$ & $(1.672)$ \\
\hline \multirow[t]{2}{*}{ Covers dental } & -0.252 & $-0.557 \dagger$ & -0.297 & $-1.137^{*}$ \\
\hline & $(0.252)$ & $(0.315)$ & $(0.255)$ & $(0.542)$ \\
\hline \multirow[t]{2}{*}{ Covers maternity } & $-1.577^{\dagger}$ & -1.205 & $-2.016^{*}$ & $-3.115^{\dagger}$ \\
\hline & $(0.898)$ & $(0.938)$ & $(0.900)$ & $(1.838)$ \\
\hline \multirow{2}{*}{$\begin{array}{l}\text { Covers alcoholism related } \\
\text { illness }\end{array}$} & 0.408 & 0.650 & 0.162 & 0.478 \\
\hline & $(0.424)$ & $(0.458)$ & $(0.431)$ & $(0.697)$ \\
\hline \multirow{2}{*}{$\begin{array}{l}\text { Limits out-of-pocket } \\
\text { expenses }\end{array}$} & $1.620^{*}$ & $1.591^{*}$ & $1.369 *$ & $2.209^{*}$ \\
\hline & $(0.461)$ & $(0.487)$ & $(0.472)$ & $(0.799)$ \\
\hline \multirow[t]{2}{*}{ Unincorporated type } & $-1.761 *$ & $-1.593 *$ & $-1.525^{*}$ & $-2.098^{*}$ \\
\hline & $(0.433)$ & $(0.479)$ & $(0.443)$ & $(0.735)$ \\
\hline \multirow[t]{2}{*}{ Non-profit type } & -0.350 & -0.229 & -0.597 & 0.490 \\
\hline & $(0.451)$ & $(0.542)$ & $(0.460)$ & $(0.965)$ \\
\hline \multirow[t]{2}{*}{ FSA $* \operatorname{Dev}[$ Marginal tax rate] } & -- & 0.003 & -- & -0.054 \\
\hline & & $(0.041)$ & & $(0.100)$ \\
\hline \multirow{2}{*}{$\begin{array}{l}\text { FSA*Dev[Payroll per } \\
\quad \text { worker }(000)]\end{array}$} & -- & $-0.033 \dagger$ & -- & -0.020 \\
\hline & & $(0.018)$ & & $(0.044)$ \\
\hline \multirow{2}{*}{$\begin{array}{l}\text { FSA } * \text { Dev[Percent } \\
\text { unionized }]\end{array}$} & & 0.002 & & -0.008 \\
\hline & & $(0.012)$ & & $(0.030)$ \\
\hline
\end{tabular}

(continued) 
(Table 3 continued)

\begin{tabular}{|c|c|c|c|c|}
\hline \multirow{2}{*}{\multicolumn{2}{|c|}{$\begin{array}{l}\text { FSA*Dev[Percent } \\
\text { employees }>54 \text { years old }]\end{array}$}} & (2) & (3) & (4) \\
\hline & & $\begin{array}{c}0.003 \\
(0.018)\end{array}$ & & $\begin{array}{c}0.003 \\
(0.051)\end{array}$ \\
\hline \multicolumn{2}{|l|}{$\begin{array}{l}\text { FSA*Dev[Percent female } \\
\text { employees] }\end{array}$} & $\begin{array}{l}-0.007 \\
(0.009)\end{array}$ & & $\begin{array}{l}-0.010 \\
(0.027)\end{array}$ \\
\hline \multicolumn{2}{|l|}{$\begin{array}{l}\text { FSA*Dev[Number of } \\
\text { employees in the location] }\end{array}$} & $\begin{array}{l}-0.003 \\
(0.008)\end{array}$ & & $\begin{array}{c}0.009 \\
(0.050)\end{array}$ \\
\hline \multicolumn{2}{|l|}{$\begin{array}{l}\text { FSA*Dev[Blue Cross/Blue } \\
\text { Shield] }\end{array}$} & $\begin{array}{r}1.510^{*} \\
(0.555)\end{array}$ & & $\begin{array}{r}5.080^{*} \\
(1.622)\end{array}$ \\
\hline \multicolumn{2}{|l|}{$\begin{array}{l}\text { FSA*Dev[Covers } \\
\text { prescription drugs] }\end{array}$} & $\begin{array}{l}-0.732 \\
(0.966)\end{array}$ & & $\begin{array}{c}2.973 \\
(3.024)\end{array}$ \\
\hline \multicolumn{2}{|l|}{ FSA*Dev[Covers prenatal] } & $\begin{array}{l}-1.872 \\
(2.400)\end{array}$ & & $\begin{array}{r}-13.689^{\dagger} \\
(7.571)\end{array}$ \\
\hline \multicolumn{2}{|l|}{ FSA $*$ Dev[Covers dental $]$} & $\begin{array}{c}1.059 \\
(0.503)\end{array}$ & & $\begin{array}{c}2.633 \\
(1.445)\end{array}$ \\
\hline \multicolumn{2}{|l|}{ FSA*Dev[Covers maternity] } & $\begin{array}{l}-5.930 \\
(3.296)\end{array}$ & & $\begin{array}{c}-0.999 \\
(13.610)\end{array}$ \\
\hline \multicolumn{2}{|l|}{ FSA $*$ Dev $[$ Covers } & $\begin{array}{l}-2.132^{\dagger} \\
(1.166)\end{array}$ & & $\begin{array}{l}-3.137 \\
(3.844)\end{array}$ \\
\hline \multicolumn{2}{|l|}{$\begin{array}{l}\text { FSA*Dev[Limits out-of- } \\
\text { pocket expenses] }\end{array}$} & $\begin{array}{c}0.087 \\
(1.426)\end{array}$ & & $\begin{array}{l}-6.515 \\
(4.912)\end{array}$ \\
\hline \multicolumn{2}{|l|}{$\begin{array}{l}\text { FSA*Dev[Unincorporated } \\
\text { type] }\end{array}$} & $\begin{array}{l}-1.370 \\
(1.075)\end{array}$ & & $\begin{array}{c}4.571 \\
(3.464)\end{array}$ \\
\hline \multicolumn{2}{|l|}{ FSA*Dev[Non-profit type] } & $\begin{array}{l}-0.280 \\
(0.834)\end{array}$ & & $\begin{array}{l}-3.374 \\
(2.321)\end{array}$ \\
\hline Industry dummies (9) & yes & yes & yes & yes \\
\hline State dummies (10) & yes & yes & yes & yes \\
\hline$\overline{\mathrm{N}}$ & 7391 & 7391 & 7391 & 7391 \\
\hline F-test & $7.25^{*}$ & $5.44^{*}$ & $7.36^{*}$ & $5.05^{*}$ \\
\hline \multicolumn{2}{|c|}{$\begin{array}{l}\text { Wu-Hausman endogeneity test of FSA } \\
\text { (and interaction variables) Ho: } \\
\text { regressors are endogenous }\end{array}$} & & $10.29 *$ & $2.59 *$ \\
\hline F-test Ho: interaction terms $=$ & & $2.24 *$ & & $2.07 *$ \\
\hline
\end{tabular}

Robust standard error in parenthesis, ${ }^{*}, \dagger$ significant at $5 \%$ and $10 \%$ level, respectively. 
Table 4. Magnitudes and robustness checks

\begin{tabular}{|c|c|c|c|c|}
\hline & $\begin{array}{c}\text { Average increase in gross } \\
\text { coinsurance rate }(\gamma) \\
(1)\end{array}$ & $\begin{array}{c}\mathrm{E}\left[\kappa_{\mathrm{i}}^{0}\right] \\
(2)\end{array}$ & $\begin{array}{c}\mathrm{E}\left[1-\tau_{\mathrm{i}}\right] \mathrm{E}\left[\kappa_{\mathrm{i}}^{1}\right] \\
(3)\end{array}$ & $\begin{array}{c}\text { Increase in net coinsurance } \\
\text { for average plan: } \\
E\left[1-\tau_{i}\right] E\left[\kappa_{i}^{1}\right]-E\left[\kappa_{i}^{0}\right] \\
(4)\end{array}$ \\
\hline Table 3 column 4 & 7.31 & 15.56 & 15.71 & 0.15 \\
\hline First stage as linear probability & $\begin{array}{c}(1.93) \\
8.38\end{array}$ & $\begin{array}{l}(0.46 \\
15.20\end{array}$ & $\begin{array}{l}(1.06) \\
16.20\end{array}$ & $\begin{array}{c}(1.16) \\
1.00\end{array}$ \\
\hline $\begin{array}{l}\text { model } \\
\text { Include number of plans as a RHS } \\
\text { variable }\end{array}$ & $\begin{array}{l}(2.35) \\
7.78\end{array}$ & $\begin{array}{l}(0.63) \\
15.46\end{array}$ & $\begin{array}{l}(1.26) \\
15.97\end{array}$ & $(1.41)$ \\
\hline Using firm averages $(n=6525)$ & $\begin{array}{l}5.96 \\
(2.12)\end{array}$ & $\begin{array}{l}15.75 \\
(0.45)\end{array}$ & $\begin{array}{l}14.91 \\
(1.20)\end{array}$ & $\begin{array}{l}-0.84 \\
(1.28)\end{array}$ \\
\hline $\begin{array}{l}\text { Include number of employees as an } \\
\text { instrument }\end{array}$ & $\begin{array}{c}6.25 \\
(1.57)\end{array}$ & $\begin{array}{l}15.84 \\
(0.29)\end{array}$ & $\begin{array}{l}15.18 \\
(0.92)\end{array}$ & $\begin{array}{l}-0.66 \\
(0.97)\end{array}$ \\
\hline \multicolumn{5}{|l|}{ Dropping instruments: } \\
\hline Firm's age & $\begin{array}{c}6.76 \\
(2.38)\end{array}$ & $\begin{array}{l}15.60 \\
(0.62)\end{array}$ & $\begin{array}{l}15.36 \\
(1.25)\end{array}$ & $\begin{array}{l}-0.24 \\
(1.40)\end{array}$ \\
\hline $\begin{array}{l}\text { Percent employees eligible for } \\
\text { health insurance }\end{array}$ & $\begin{array}{c}7.43 \\
(2.00)\end{array}$ & $\begin{array}{l}15.55 \\
(0.46)\end{array}$ & $\begin{array}{l}15.79 \\
(1.11)\end{array}$ & $\begin{array}{c}0.24 \\
(1.20)\end{array}$ \\
\hline Has location in other states & $\begin{array}{c}6.96 \\
(2.82)\end{array}$ & $\begin{array}{l}15.70 \\
(0.61)\end{array}$ & $\begin{array}{l}15.57 \\
(1.56)\end{array}$ & $\begin{array}{l}-0.13 \\
(1.67)\end{array}$ \\
\hline Competitor in state & $\begin{array}{c}6.84 \\
(1.88)\end{array}$ & $\begin{array}{l}15.65 \\
(0.46)\end{array}$ & $\begin{array}{l}15.45 \\
(1.03)\end{array}$ & $\begin{array}{l}-0.20 \\
(1.13)\end{array}$ \\
\hline
\end{tabular}

Notes: The average marginal tax rate (State plus federal plus 7.65 percent Social Security and Medicare) in the sample is 31.3 percent, so $\mathrm{E}\left[1-\tau_{\mathrm{i}}\right]=0.687$ in column (3).

The dropped instruments were included in the 2 nd stage coinsurance rate regressions, and none were statistically significant. 